\title{
Micro-Computed Tomography and Finite Element Method Study of Open- Cell Porous Materials
}

\author{
Tomasz Wejrzanowski $^{\text {a }}$, Jakub Skibinski, Karol Cwieka and Krzysztof J. Kurzydlowski \\ Faculty of Materials Science and Technology, Warsaw University of Technology, Poland
}

\begin{abstract}
In the present paper the characterization of structure and properties of open-cell porous materials by highresolution x-ray micro-computed tomography $(\mu \mathrm{CT})$ and finite element method (FEM) is addressed. The unique properties of open porosity foams make them interesting in a range of applications in science and engineering such as energy absorbers, lightweight construction materials or heat insulators. Consequently, a detailed knowledge of structure as well as mechanical properties (i.e. Young's Modulus, Poisson's Ratio) of such foams is essential. The resulting pixel size of the $\mu \mathrm{CT}$ was $40 \mu \mathrm{m}$, which enabled satisfactory visualization of the complex foam structure and quantitative characterization. Foam morphology was studied on post-processed computed tomography images, while mechanical properties were analyzed with use of the finite element method on numerical model obtained from $\mu \mathrm{CT}$ results.
\end{abstract}

\section{Introduction}

High porosity open-cell foam materials are significantly interesting in commercial applications such as energy absorbers, elements for lightweight constructions, structural dampers, sound absorbers and heat insulators [1-5]. Both structure and mechanical properties of such materials have been the subject of intensive research. Structural parameters of commercially available foams have been a subject of studies with use of X-ray microcomputed tomography [6-10]. $\mu \mathrm{CT}$ is a technique widely used to study various porous subjects, even the rocks $[11,12]$. Structural descriptors such as porosity, specific surface, mean strut diameter and mean pore diameter are most commonly used for characterization of complex structure of foam materials.

Mechanical properties have also been a subject of extensive research, and includes experimental [13,14], analytical [15] and numerical [16,17] approaches. Numerical analysis uses both simplified model structures, and calculation models derived from $\mu \mathrm{CT}$ data [18]. Finite element method analysis of models developed basing on tomography results allows the consideration of the complex, random mesostructure of the material [19], therefore it has been chosen for present analysis.

The primary purpose of this study is to present results of morphology assessment supplemented with numerical simulations for typical foam structures. Five foams of nominal pore densities from 10 to $50 \mathrm{ppi}$ and porosities in the range from 71 to $74 \%$ are investigated.

\section{Materials and Methods}

In the present study five commercially available aluminum foam specimens were investigated. Materials with nominal pore densities of $10,20,30,40$ and 50 pores per inchwere used.

To this end, $\mu \mathrm{CT}$ scans of samples were performed. The three dimensional image acquisition was performed using X-Radia XCT-400 made by SkyScan under acceleration voltage of $150 \mathrm{kV}$ and current of $50 \mathrm{~A}$, which assured a voxel resolution in the range from 15 to 45 $\mu \mathrm{m} /$ voxel. A three-dimensional reconstruction of the sample was generated by collecting a series of absorption radiographs of the cellular material. A total of 900 projections of the $2 \mathrm{D}$ radiography images were reconstructed using XCT-reconstruction software. This process resulted in a set of 256-level grayscale bitmapformat tomograms. In order to recover the actual geometry of the specimen, this dataset had to be filtered and binarized, i.e., each pixel had to be prescribed with a value 0 or 1 (black or white) denoting void or solid phase. Both processes were performed using SkyScancTAN software. First, a median filter was used to remove the noise. This filtering procedure has an additional advantage of smoothing the boundaries. Then, an appropriate threshold level for binarization was chosen. Subsequently, a 3D structural analysis was performed.

Numerical analyses of elastic properties of aluminum porous structures consisted of obtaining threedimensional models of complex geometries and FE analysis.

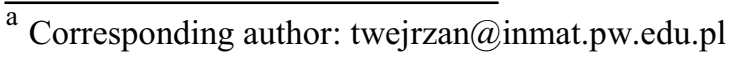


Precise finite element analysis requires adaptive numerical models with minimal number of elements. Investigated specimens have complex topology, therefore it is necessary to perform a series of operations on the high resolution $\mu \mathrm{CT}$ images to obtain valid computational mesh for FEM simulations: conversion of images to three dimensional surface object (STL format), reduction of number of faces of 3D model, conversion of 3D model to cloud of points to eliminate errors and smoothing of the structure.

In the first step a series of BMP images is conversed into numerical model based on binarized image and voxel size determined during tomography. Representation of three dimensional object is created with use of triangular elements - the surface of the sample is divided to a logical series of triangles (Fig. 1).

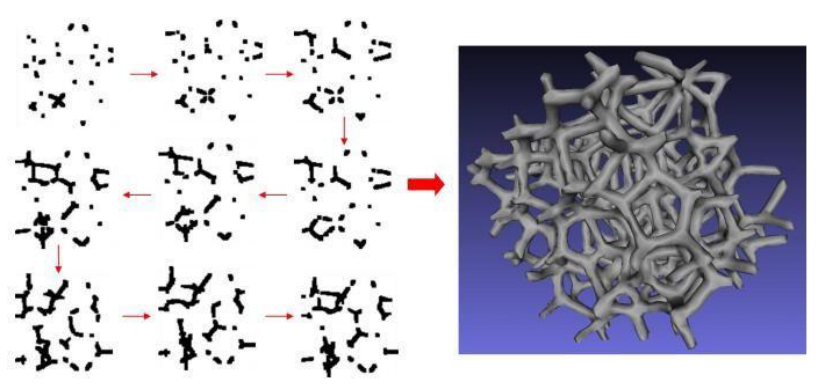

Figure 1. Bitmap images conversion to STL file.

The geometry of the sample in form of STL file has a high number of elements due to significant number of struts of porous foams combined with irregular shape of pore connections. Reduction of number of faces is necessary to optimize calculation time. Inaccuracy of conversion process causes the STL geometry to exhibit errors such as double edges or crossing surfaces. To fix such issues surface geometry can be converted into cloud of points, which integrates problematic areas. Next step is generating new three dimensional mesh with valid topology. The last step is smoothing of obtained digitalized geometry.

Subsequently, after processing $\mu \mathrm{CT}$ images of foam structures with 10-50ppi (pores per inch), finite element meshes were generated on model geometries. Parts of obtained meshed models are shown in Fig. 2.

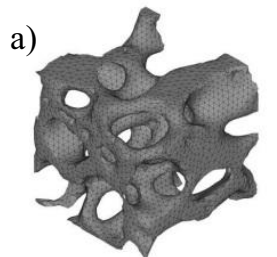

d)

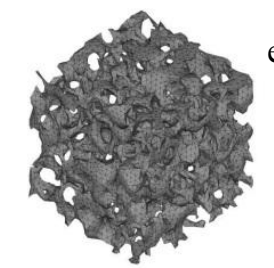

b)

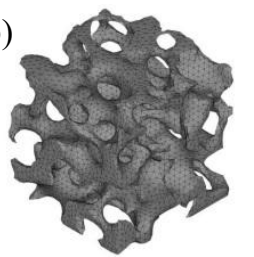

c)

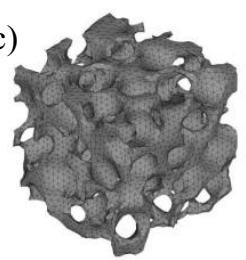

e)

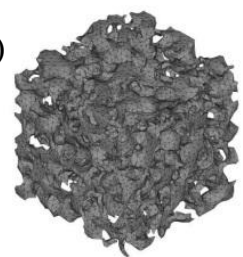

Figure 2. Example parts of meshed geometrical models for FEM analysis: a) 10 ppi, b) 20 ppi, c) $30 \mathrm{ppi}$, d) 40 ppi, e) 50 ppi
Finite element analysis, conducted using ANSYS software, can be separated into the following steps: preprocessing, solution and post-processing.

Preprocessing stage included import of the meshed geometry models, defining material properties and boundary conditions. Ideal elastic material model for matrix has been defined by following sets of isotropic Young's modulus and Poisson's ratio of E=69GPa, $v=0.33$ for aluminum. Boundary conditions corresponded to uniaxial compression test.

In order to investigate the anisotropy, investigated structures were subjected to numerical simulations of uniaxial compression in three perpendicular directions. An algorithm was implemented using APDL language (ANSYS software) which included commands allowing to import meshed geometry file, define boundary conditions, set solution parameters, calculate results, post-process obtained data and save them into the output file. Block diagram of abovementioned algorithm is depicted in Fig. 3.

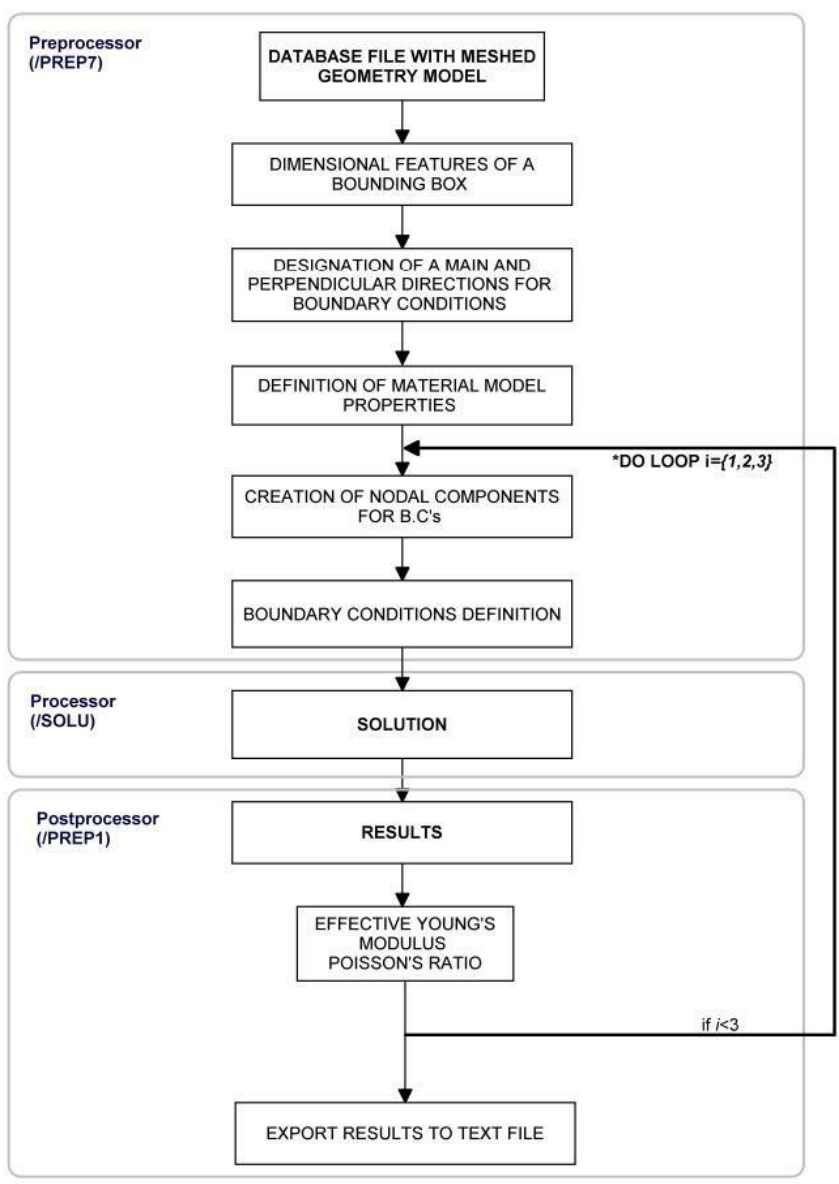

Figure 3. Finite element analysis algorithm for investigating mechanical properties of foams

Each model was constrained on two nodal components located at the opposite sides - zero displacement at the bottom and displacement equal to $0.1 \%$ of initial edge length at the top. Additionally one of the nodes from the bottom was constrained in three directions (ux, uy anduz displacement were fixed). The value of macroscopic engineering stresses has been evaluated as a quotient of the sum of the nodal reaction 
Table 1. Results of image analysis.

\begin{tabular}{|c|c|c|c|c|}
\hline $\begin{array}{c}\text { Pore size } \\
{[\text { Pores Per Inch] }}\end{array}$ & $\begin{array}{c}\text { Porosity } \\
{[\%]}\end{array}$ & $\begin{array}{c}\text { Specific surface } \\
{[1 / \mathrm{mm}]}\end{array}$ & $\begin{array}{c}\text { Mean pore diameter } \\
{[\mathrm{mm}]}\end{array}$ & $\begin{array}{c}\text { Mean strut diameter } \\
{[\mathrm{mm}]}\end{array}$ \\
\hline 10 & 74,01 & 0,779 & 3,53 & 1,37 \\
\hline 20 & 71,82 & 1,132 & 2,29 & 1,21 \\
\hline 30 & 72,22 & 1,227 & 2,08 & 0,896 \\
\hline 40 & 73,62 & 1,448 & 1,63 & 0,523 \\
\hline 50 & 75,42 & 1,847 & 1,16 & 0,45 \\
\hline
\end{tabular}

forces $\Sigma$ Fn divided by initial engineering cross-section area $\mathrm{A}=\mathrm{a}^{2}$.

$$
\sigma=\frac{\sum F_{n}}{A}=\frac{\sum F_{n}}{a^{2}}
$$

The engineering strain values were obtained by dividing applied displacement by initial height of the computed structure.

\section{Results and discussion}

Complete data from three dimensional image analysis, performed using SkyScanCTan software, is listed in Table 1. The presented data does not refer to the entire foam because the scanning process could not cover the entire foam specimen. Serious disturbances occurred on the borders of measured samples. Additionally, the total scanned volume was related to the scanning resolution. 10 and 20 ppi foam scans were performed with resolution of $45 \mu \mathrm{m}$ and resulted in a cubic shaped geometry of 35 $\mathrm{mm}$ edge length. Such resolutionis sufficient for obtaining precise representation of complex foam geometry, and the obtained sample size seems sufficient to be treated as representative regarding the mean pore size of foams. The 30 ppi foam was scanned at $25 \mu \mathrm{m}$ resolution (obtained edge length of $25 \mathrm{~mm}$ ) due to smaller size of struts for this structure. 40 and 50 ppi foams required scanning resolution of $12 \mu \mathrm{m}$, because scans with lower resolution exhibited distorted foam topology. The obtained edge length of these foams was $15 \mathrm{~mm}$.

Similar foam specimens investigations using $\mu \mathrm{CT}$ can be found in literature $[16,18,19]$. Good correlation between values obtained for studied samples and data reported by other researchers was obtained. Some discrepancies can also be found in [20], however they can be attributed to different preprocessing of the specimen and insufficient scanning resolution.

Mechanical properties calculated using finite element method are listed in Table 2.Open-cell foam structures are characterized by randomly distributed cells. Investigation of such structures requires consideration of the size of representative volume in order to obtain reliable macroscopic mechanical properties of the material. Recommendations in literature range from 5 cells [21,22] to 10 cells [23,24]. Models used in this study comprise of 8 or more cells per edge length, therefore they seem to constitute a representative volume.
The results obtained are in accordance with data reported in literature for similar structures $[14,16,18]$. Moreover, anisotropy of mechanical properties is detected for every studied sample. Calculated values of Young's Modulus vary from $4 \%$ for 50 ppi foam, through $13 \%$ for 30 and 40 ppi samples, up to $35 \%$ for 10 ppi material. Such material behavior was also observed in [16].

Results obtained also indicate, that mean strut diameter is not the primary decisive factor determining Young's Modulus Value (Fig. 4 a). Literature indicates lower stiffness of the material for higher porosity. The overall trend obtained in the present study also suggests, that structures with lower porosities exhibit higher Young's Modulus, however the range of porosity value of studied samples is quite narrow, and the results obtained do not linearly depend on porosity (Fig. 4 b).

a)
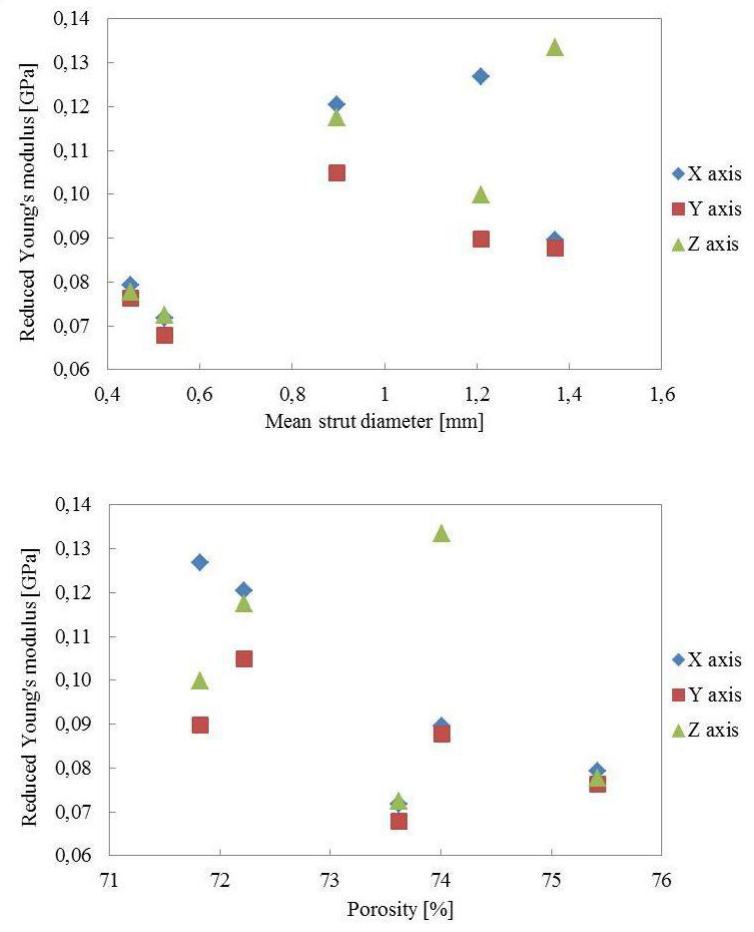

Figure 4. Calculated values of relative Young's modulus against: a) mean strut diameter and b) porosity 
Table 2. Mechanical properties calculated using FEM

\begin{tabular}{|c|c|c|c|c|c|c|c|c|c|}
\hline \multirow{2}{*}{$\begin{array}{c}\text { Pore size [Pores } \\
\text { Per Inch] }\end{array}$} & \multicolumn{4}{|c|}{ Young's Modulus [GPa] } & \multicolumn{4}{|c|}{ Reduced Young's Modulus } & \multicolumn{3}{|c|}{ Poisson's Ratio } \\
\cline { 2 - 10 } & $\mathrm{X}$ & $\mathrm{Y}$ & $\mathrm{Z}$ & $\mathrm{X}$ & $\mathrm{Y}$ & $\mathrm{Z}$ & $\mathrm{XY}$ & $\mathrm{YZ}$ & $\mathrm{ZX}$ \\
\hline 10 & 6,272 & 6,144 & 9,338 & 0,090 & 0,088 & 0,133 & 0,213 & 0,286 & 0,24 \\
\hline 20 & 8,876 & 6,294 & 6,994 & 0,127 & 0,090 & 0,100 & 0,254 & 0,188 & 0,227 \\
\hline 30 & 8,425 & 7,344 & 8,226 & 0,120 & 0,105 & 0,118 & 0,225 & 0,250 & 0,245 \\
\hline 40 & 5,021 & 4,757 & 5,063 & 0,072 & 0,068 & 0,072 & 0,226 & 0,214 & 0,192 \\
\hline 50 & 5,552 & 5,336 & 5,432 & 0,079 & 0,076 & 0,078 & 0,209 & 0,192 & 0,211 \\
\hline
\end{tabular}

\section{Summary}

This work addressed the determination of structural parameters and mechanical properties of open-cell foam materials. Young's modulus, as well as Poisson's ratio, exhibits anisotropy. Combination of used analysis tools, i.e. micro-computed tomography and finite element analysis, gives new possibilities in studying both structural parameters and properties of geometrically complex materials such as foams. Exhibited structural differences and anisotropy of studied samples can be crucial in applications, where stiffness of used material is of primary importance, since more than $30 \%$ difference in Young's Modulus value was observed in present analysis. The results obtained were compared against other researchers' data for similar structures and good agreement was found. In all cases, foam anisotropy was detected.

\section{Acknowledgement}

The work was financially supported by the National Centre for Research and Development, contract no. BG1/GASLUPSEJSM/13.

\section{References}

1. M.F. Ashby, A. Evans, N.A. Fleck, L.J. Gibson, J.W. Hutchinson, H.N.G. Wadley, Metal Foams: A Design Guide, Butterworth-Heinemann (2000)

2. J. Baumeister, J. Banhart, M. Weber, Aluminium foams for transport industry, Materials \& Design 18, Issue 4, p. 217-220 (1997)

3. L.J. Gibson, M.F. Ashby, Cellular Solids: Structure and properties, Oxfrod: Pergamon Press (1988)

4. T. Wejrzanowski, J. Skibinski, J. Szumbarski, K.J. Kurzydlowski, Structure of foams modeled by Laguerre-Voronoi tesselations, Computational Materials Science 67, p. 216-221 (2013)

5. J. Skibinski, K. Cwieka, T. Kowalkowski, B. Wysocki, T. Wejrzanowski, K. J. Kurzydlowski, The influence of pore size variation on the pressure drop in open-cell foams, Materials and Design 87 (2015) pp. 650-655
6. W. Regulski, J. Szumbarski, L. Wollk-Laniewski, K. Gumowski, J. Skibinski, M. Wichrowski, T. Wejrzanowski, Pressure drop in flow across ceramic foams - A numerical and experimental study, Chemical Engineering Science, Volume 137, p. 32033 (2015)

7. C. Veyhl, I.V. Belova, G.E. Murch, T. Fiedler, Finite element analysis of the mechanical properties of cellular aluminium based on micro-computed tomography, Materials Science and Engineering A, Volume 528, Issues 13-14 p. 4550-4555 (2011)

8. A.M. Parvanian, M. Saadatfar, M. Panjepour, A. Kingston, A.P. Sheppard, The effects of manufacturing parameters on geometrical and mechanical properties of copper foams produced by space holder technique, Materials and Design Volume 53, p. 681-690 (2014)

9. N. Taherishargh N., M.A. Sulong M.A., I.V. Belova I.V., G.E. Murch G.E., T. Fiedler T., On the particle size effect in expanded perlite aluminium syntactic foam, Materials and Design Volume 66, pages 294 303 (2015)

10. J. Skibinski, T. Wejrzanowski, J. Szumbarski, K.J. Kurzydłowski, Computational design of the flow properties of foams, WIT Transactions on Engineering Sciences, Vol 74 p. 109-118, ISBN 978-1-84564-6004 (2012)

11. L. Kaczmarek, G. Machowski, M. Maksimczuk, T. Wejrzanowski 2015 - The use of high-resolution X-ray computed microtomography in structural analysis of the Miocene sandstones of the Carpathian Foredeep (in Polish with English summary). Nafta-Gaz 9, p. 15-22 (2015).

12. L. Kaczmarek, m. Maksimczuk, t. Wejrzanowski, a. Krzyzak, High-resolution X-ray microtomography and nuclear magnetic resonance study of a carbonate reservoir rock, 15th International Multidisciplinary Scientific GeoConference SGEM 2015, ISBN 978619-7105-31-5/ISSN 1314-2704, June 18-24, 2015, Book1 Vol. 1, 779-786 pp,

13. W.Y. Jang, S. Kyriakides, On the crushing of aluminum open-cell foams: Part I. Experiments, International Journal of Solids and Structures 46 (3) p. 617-634 (2009)

14. X. Badiche, S. Forest, T. Guibert, Y. Bienvenu, J.D. Bartout, P. Ienny, M. Croset, H. Bernet, Mechanical 
properties and non-homogeneous deformation of open-cell nickel foams: Application of the mechanics of cellular solids and of porous materials, Materials Science and Engineering A 289p. 276-288 (2000)

15. H.X. Zhu, J.F. Knott, N.J. Mills, Analysis of the elastic properties of open-cell foams with tetrakaidecahedral cells, Journal of the Mechanics and Physics of Solids 45 (3), p. 319-343 (1997)

16. C. Veyhl, I.V. Belova. G.E. Murch, T. Fiedler, Finite element analysis of the mechanical properties of cellular aluminium based on micro-computed tomography, Materials Science and Engineering A 528, p. 4550-4555 (2011)

17. Y. An, C.E. Wen, P.D. Hodgson, C. Yang, Investigation of cell shape effect on the mechanical behavior of open-cell metal foams, Computational Materials Science 55, p. 1-9 (2012)

18. T. Fiedler, I.V. Belova, G.E. Murch, $\mu$-CT-based finite element analysis on imperfections in opencelled metal foam: Mechanical properties', Scripta Materialia, 67 455-458 (2012)

19. J. Große, B. Dietrich, G.I. Garrido, P. Habisreuther, N. Zarzalis, H. Martin, M. Kind, B. Kraushaar-
Czarnetzki, Morphological characterization of ceramic sponges for applications in chemical engineering, Industrial \& Engineering Chemistry Research 48 (23) p. 10395-10401 (2009)

20. J. Große, B. Dietrich, H. Martin, M. Kind, J. Vicente, E.H. Hardy, Volume image analysis of ceramic sponges, Chemical Engineering and Technology 31(2) p. 307-314 (2008)

21. A.P. Roberts, E.J. Garboczi, Elastic properties of model random three-dimensional open-cell solids, Journal of the Mechanics and Physics of Solids Volume 50 p. 33-35 (2002)

22. A.P. Roberts, E.J. Garboczi, Elastic moduli of model random three-dimensional closed-cell cellular solids, Acta Materialia 49 p. 189-197 (2001)

23. T. Hipke, G. Lange, R. Poss, Tashenbuch fur Aluminiumschaume, 1. Auflage ed., AluminiumVerlag (2007)

24. E.W. Andrews, G. Gioux, P. Onck, L.J. Gibson, Size effects in ductile cellular solids. Part II: experimental results, International Journal of Mechanical Sciences 43 p. 701-713 (2001) 